\title{
SYMMETRICAL PIEZOELECTRIC MICROACTUATORS FOR MAGNETIC DISK DRIVES
}

\author{
K. Kurihara*, T. Mita*, M. Hida* and S. Koganezawa** \\ * Materials and Environmental Engineering Laboratories \\ Fujitsu Laboratories Ltd., \\ 10-1 Morinosato Wakamiya, Atsugi, Kanagawa 243-0197, JAPAN \\ e-mail:kurihara@flab.fujitsu.co.jp \\ mita@flab.fujitsu.co.jp \\ masaharu@flab.fujitsu.co.jp \\ **HDD Development Department, Fujitsu Limited \\ 4-1-1 Kamikodanaka, Nakahara, Kawasaki, 211-8588, JAPAN \\ e-mail: skoga@jp.fujitsu.com
}

\begin{abstract}
We have developed a novel piezoelectric microactuator for the head-slider drive dual-stage actuator systems in magnetic disk drives. This microactuator is based on a symmetrical structure and a symmetrical operation. The piezoelectric actuator devices used in the system are simple rectangular multilayered structure. A prototype model with pico-slider and the head suspension has been tested to demonstrate $0.8 \mu \mathrm{m}$ displacement at a dc applied voltage of $30 \mathrm{~V}$ and fundamental resonant frequency over $20 \mathrm{kHz}$.
\end{abstract}

\section{INTRODUCTION}

In recent years, the areal density of magnetic disk drive has increased by $70 \%$ to $100 \%$ every year, mainly based on the improvement of recording heads and mediums. There have been an increasing demand of wider servo band to achieve stable operation at a higher track density. However, the servo bandwidth of voice-coil motor (VCM) systems, which are widely used for positioning the magnetic head, is limited by the mechanical resonances of the carriage, coil, and suspension.

One possible solution respond to a higher track density is by using dual-stage actuator systems. Some types of microactuators have been proposed to attain a wider servo bandwidth. Current research on microactuator design may be divided into three types. First is driving a head suspension assembly [1], second is driving a head slider, and the last is driving a head element. Suspension driving type has a problem of in eliminating the effect of suspension resonance. Head element driving type has some difficulty in process integration with head process and MEMS actuator process. The merit of the slider driving type is wider servo band width compared to the suspension driving type. Another merit is that no additional process is needed to the head slider process.

In this paper, a novel piezoelectric microactuator based on a symmetrical structure for the head-slider drive dual-stage actuator system will be introduced.

\section{Design of piezoelectric microactuator \\ 2. 1 Structure}

Figure 1 shows a schematic structure of our new piezoelectric microactuator. Two multilayered ceramic piezoelectric actuators are placed between a head slider and a suspension. Those actuators are bonded diagonally to a slider and suspension.

The unique feature of the actuator is a symmetrical structure. Because of conformation of a center of gravity and an axis of rotation, Excitation of resonance of suspension will be minimized. This is an important concept of our new actuator system.

Another feature of the actuator is very simple structure, especially using simple shaped piezoelectric actuator elements which are same as widely used rectangular shaped one.

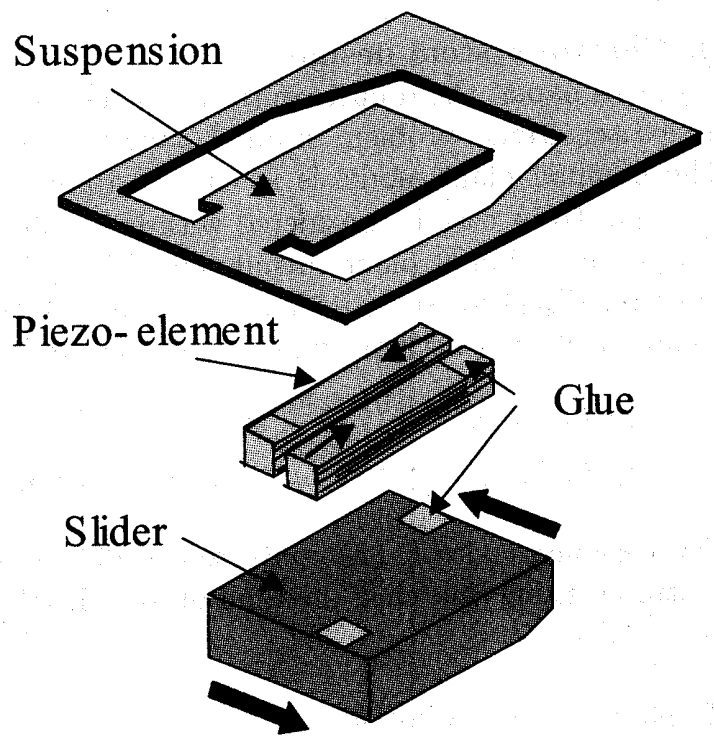

Fig.1 Schematic structure of microactuator 
One more feature of the actuator is using high performance piezoelectric ceramic materials based on $\mathrm{Pb}(\mathrm{Ni}, \mathrm{Nb}) \mathrm{O}_{3}-\mathrm{PbTiO}_{3}-\mathrm{PbZrO}_{3} \quad$ (PNN-PT-PZ) system developed at Fujitsu Laboratories Ltd [2]. This piezoelectric ceramic has a high piezoelectric constant and is suitable for actuator applications.

\subsection{Target and Design}

In this study, design targets are wide slider moving stroke of $1 \mu \mathrm{m}$ at $30 \mathrm{~V}$ operation and high resonance frequency over $20 \mathrm{kHz}$ for wider servo band width. FEM analysis was performed in order to get a suitable design which cover the design specifications. The model used in this study is whole HGA consisting of $30 \%$ pico-slider, two piezoelectric microactuator elements and suspension. The suspension also consists of a gimbal and loadbeam. The air springs are also taken into account because the slider is flying on rotating disk. The detailed design was fixed by comparing results of static analysis, modal analysis, and frequency response analysis.

\subsection{Measurements of Mechanical properties}

Mechanical properties of fabricated HGA using piezoelectric microactuator designed by FEM analysis were measured using a laser Doppler vibrometer.

\subsection{Simulation}

Figure 2 shows a result of displacement distribution by FEM analysis of the HGA. The displacement of the head element is $0.93 \mu \mathrm{m}$ at $30 \mathrm{~V}$ applied. This is very close to our displacement target of $1 \mu \mathrm{m}$ at $30 \mathrm{~V}$ applied.

Figure 3 shows a simulation result of frequency response. Main resonance frequency of the actuator is $26.3 \mathrm{kHz}$ that is higher than our target of $20 \mathrm{kHz}$. Note that excitation of the suspension near $14 \mathrm{kHz}$ is very small compared to that of the actuator. The reason of this small resonance is a unique feature of our symmetrical actuator structure.

\subsection{Measurement}

The measured displacement at head edges (head element side and carriage side) at $30 \mathrm{~V}$ applied were 0.91 $\mu \mathrm{m}$ and $0.89 \mu \mathrm{m}$ respectively. Those are very close to calculated value of $0.93 \mu \mathrm{m}$. Figure 4 shows a measured frequency response of the fabricated HGA using piezoelectric microactuator. The resonance frequency of the actuator is $25.1 \mathrm{kHz}$. This is also very close to the calculated values. Measured peaks near $14 \mathrm{kHz}$ that is excitation of the suspension are very small compared to the resonance of actuator.

\section{CONCLUSION}

A unique symmetrical piezoelectric microactuator for head-slider drive dual-stage actuator system for HDD have been investigated. Results of FEM analysis and measured data of fabricated HGA are in good agreement and show excellent vibration characteristics.

\section{REFERENCES}

[1] Koganezawa S. and Hara T., Development of Shear-Mode Piezoelectric Microactuator for Precise Head Positioning, Fujitsu Science and Technology Journal, Vol. 37, 2001, pp. 212-219.

[2] Kondo M., Hida M., Tsukada M., Kurihara K., and Kamehara N., Piezoelectric Properties of $\mathrm{PbNi1} / 3 \mathrm{Nb}$ /3O3-PbTiO3-PbZrO3 Ceramics Near the MPB, Journal of the Ceramic Society of Japan, Vol. 105, No. 8, 1997, pp. 719-721.

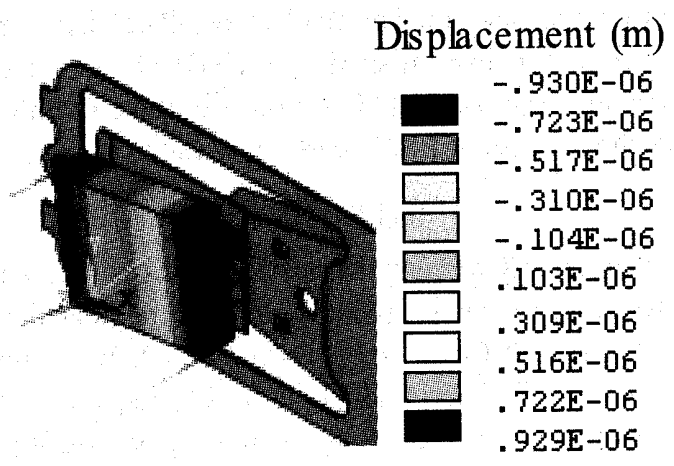

Fig. 2 FEM simulation result of displacement distribution.

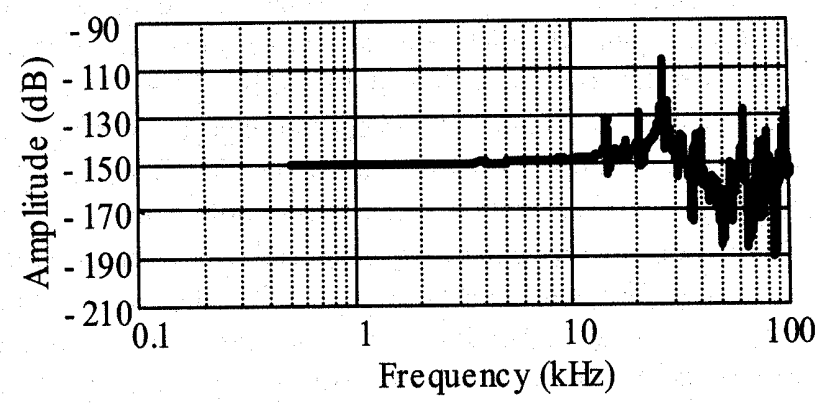

Fig. 3 Calculated frequency response

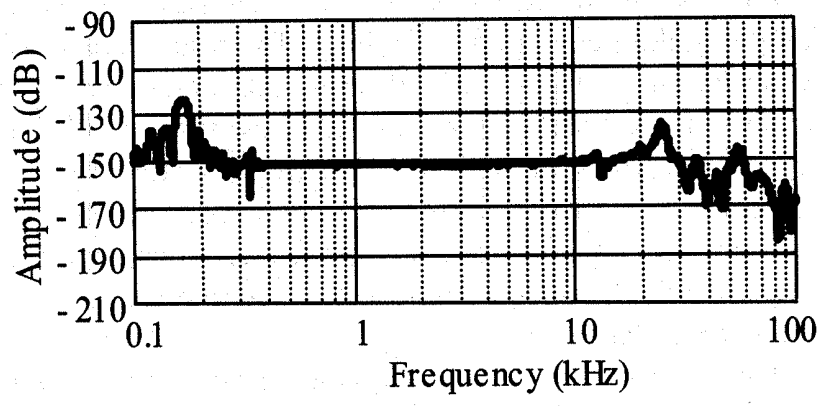

Fig. 4 Measured frequency response 